\title{
SURFACE EFFECT DUE TO INCIDENT PLANE SURFACE HORIZONTAL WAVES
}

\author{
JEFFRY K. \\ Department of Mathematics, Faculty of Mathematics and Natural Science, \\ Hasanuddin University, Jalan Perintis Kemerdekaan, 90245 Makassar, Indonesia. \\ jeffry.kusuma@gmail.com
}

\begin{abstract}
Surface effect due to incident plane surface horizontal waves through anisotropic elastic materials is studied. Mathematical formulation over the modeled earth's alluvial valley is transformed into integral equations. These integral equations altogether with the boundary condition and continuity equation are then solved numerically. The solution of these amplification effects over the half circular in homogeneous alluvial valley are shown graphically.
\end{abstract}

ABSTRAK: Kajian tentang kesan permukaan yang disebabkan oleh ombak insiden permukaan mengufuk melalui bahan-bahan elastik anisotropik telah di jalankan. Penggubalan persamaan pengamiran dibuat berdasarkan model lembah aluvium bumi. Persamaan-persamaan ini diselesaikan secara numerikal menggunakan syarat sempadan persamaan selanjar.Penyelesaian kepada kesan pembesaran ke atas model separa bulatan lembah aluvium tak homogen telah digambarkan secara grafik.

KEYWORDS: surface effect; surface horizontal wave; inhomogeneous anisotropic materials.

\section{INTRODUCTION}

One of the major concerning in engineering seismology is to understand and explain vibration properties of the soil excited by near earthquakes. Alluvial deposits, often very irregular geometrically, may affect significantly the amplitudes of incident seismic waves. The ground amplification of seismic wave on alluvial valleys have been studied by numerous authors [1-6]. Integral equation formulations have been found to be particularly useful in obtaining numerical solutions to problems of this type. In particular, Wong and Jennings [4] have used singular integral equations to solve the problem of scattering and diffraction of incident surface horizontaly $(\mathrm{SH})$ waves by canyon so farbitrary cross section. Also, Bravo [1] extended the method by considering stratified alluvial deposits. Clements and Larsson [7] extending further these integral formulation techniques by including the case of homogeneous anisotropic materials. In this paper, further extension is being made by including the case of inhomogeneous anisotropic materials. 


\section{GROUND MOTION ON AN ALLUVIAL INHOMOGENEOUS ANISOTROPIC VALLEY}

Referred to a Cartesian frame $O x_{1} x_{2} x_{3}$, let's consider an anisotropic elastic half space occupying the region $x_{2}>0$ as illustrated in Fig. 1. The half space here is divided into two regions in which the first region contains a homogeneous isotropic material with shear moduli $\mu_{i j}^{(1)}=\lambda_{i j}^{(1)}$ and the second region contains an inhomogeneous anisotropic material with the shear moduli $\mu_{i j}^{(2)}=\lambda_{i j}^{(2)}\left(\alpha_{1}^{(2)} x_{1}+\alpha_{2}^{(2)} x_{2}+\alpha_{3}^{(2)}\right)^{2}$. The materials are assumed to adhere rigidly to each other so that the displacement and stress are continuous across the interface boundary between the first and the second regions and the constants in the shear moduli satisfy the symmetry conditions $\lambda_{i j}^{(\Omega)}=\lambda_{j i}^{(\Omega)}$ for $\Omega=1.2$.

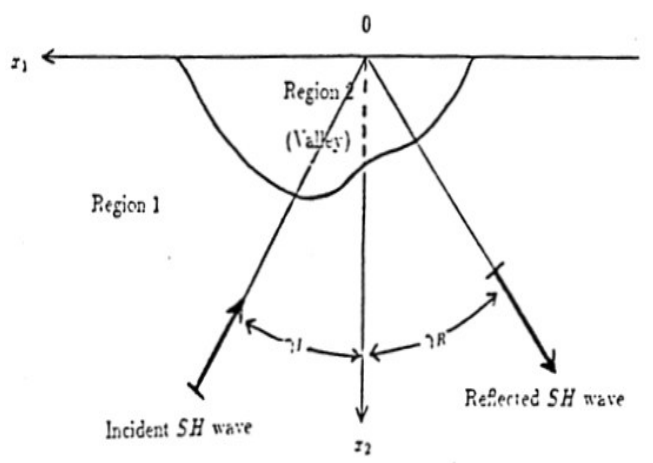

Fig. 1: Incident and reflected waves on the alluvial valley and surrounding half-space.

Let $u^{(1)}$ and $u^{(2)}$ be the displacement in the $x_{3}$ direction in the half space and the valley respectively. For the propagation of horizontally polarizes $S H$ waves, the displacement satisfies the equations of motion

$$
\lambda_{i j}^{(1)} \frac{\partial^{2} u^{(1)}}{\partial x_{i} \partial x_{j}}=\rho_{0}^{(1)} \frac{\partial^{2} u^{(1)}}{\partial t^{2}}
$$

for the region 1 and

$$
\frac{\partial}{\partial x_{i}}\left[\lambda_{i j}^{(2)}\left(\alpha_{1}^{(2)} x_{1}+\alpha_{2}^{(2)} x_{2}+\alpha_{3}^{(2)}\right)^{2} \frac{\partial u^{(2)}}{\partial x_{j}}\right]=\rho_{0}^{(2)}\left(\alpha_{1}^{(2)} x_{1}+\alpha_{2}^{(2)} x_{2}+\alpha_{3}^{(2)}\right)^{2} \frac{\partial^{2} u^{(2)}}{\partial t^{2}}
$$

for region 2 . Here $\rho_{0}^{(\Omega)}$ denotes the density, $t$ denotes the time and repeated Latin subscripts denote summation from 1 to 2 . 
IIUM Engineering Journal, Vol. 12, No. 6, 2011: Special Issue in Science and Ethics

Jeffry

In view of assuming the form of time dependence as $\exp (\iota \omega t)$, equation (1) can be reduced to

$$
\lambda_{i j}^{(1)} \frac{\partial^{2} v^{(1)}}{\partial x_{i} \partial x_{j}}+\rho_{0}^{(1)} \omega^{2} v^{(1)}=0
$$

by substituting

$$
u^{(1)}\left(x_{1}, x_{2}, t\right)=v^{(1)}\left(x_{1}, x_{2}\right) \exp (\iota \omega t) .
$$

Similarly with the equation 2. By substituting

$$
u^{(2)}\left(x_{1}, x_{2}, t\right)=v^{(2)}\left(x_{1}, x_{2}\right) \exp (\iota \omega t)
$$

we obtain

$$
\begin{gathered}
\frac{\partial}{\partial x_{i}}\left[\lambda_{i j}^{(2)}\left(\alpha_{1}^{(2)} x_{1}+\alpha_{2}^{(2)} x_{2}+\alpha_{3}^{(2)}\right)^{2} \frac{\partial v^{(2)}}{\partial x_{j}}\right]+ \\
\rho_{0}^{(2)} \omega^{2}\left(\alpha_{1}^{(2)} x_{1}+\alpha_{2}^{(2)} x_{2}+\alpha_{3}^{(2)}\right)^{2} v^{(2)}=0 .
\end{gathered}
$$

Our interest is a plane wave of unit amplitude which propagates toward the surface of the elastic half space

$$
v_{I}^{(1)}=\exp \iota \omega\left(t+\frac{x_{1}}{c_{1}}+\frac{x_{2}}{c_{2}}\right)
$$

where $c_{1}=\beta^{(1)} / \sin \gamma_{I}, c_{2}=\beta^{(1)} / \cos \gamma_{I}, \quad \beta^{(1)}$ denotes the velocity of the incident waves and $\gamma_{I}$ denotes the angle of the incident wave. Since $v_{I}^{(1)}$ in (7) propagates in the first material, it must satisfy equation (3) so that

$$
\left[\beta^{(1)}\right]^{2}=\frac{\lambda_{11}^{(1)} \sin ^{2} \gamma_{I}+2 \lambda_{12}^{(1)} \sin \gamma_{I} \cos \gamma_{I}+\lambda_{22}^{(1)} \cos ^{2} \gamma_{I}}{\rho_{0}^{(1)}}
$$


IIUM Engineering Journal, Vol. 12, No. 6, 2011: Special Issue in Science and Ethics

Jeffry

Now we consider the case when region 1 and 2 are occupied by the same material. In order to satisfy the traction free condition on $x_{2}=0$, it is necessary to have a reflected wave of the form

$$
v_{R}^{(1)}=\exp \iota \omega\left(t+\frac{x_{1}}{d_{1}}-\frac{x_{2}}{d_{2}}\right)
$$

Thus, if there are no irregularities, the free field solution of the displacement can be written as

$$
v_{O}^{(1)}=v_{I}^{(1)}+v_{R}^{(1)}
$$

The stresses are given by

$$
\sigma_{i 3}^{(1)}=\lambda_{i j}^{(1)} \frac{\partial v^{(1)}}{\partial x_{j}}
$$

so that the stress $\sigma_{23}^{(1)}$ on $x_{2}=0$ is

$$
\sigma_{23}^{(1)}=\left(\frac{\lambda_{21}^{(1)}}{c_{1}}+\frac{\lambda_{22}^{(1)}}{c_{2}}\right) \exp \left[\iota \omega\left(t+\frac{x_{1}}{c_{1}}\right)\right]+\left(\frac{\lambda_{21}^{(1)}}{d_{1}}-\frac{\lambda_{22}^{(1)}}{d_{2}}\right) \exp \left[\iota \omega\left(t+\frac{x_{1}}{d_{1}}\right)\right]
$$

This stress will be zero for all times $t$ if

$$
\begin{aligned}
& d_{1}=c_{1} \\
& \frac{1}{d_{2}}=\frac{1}{c_{2}}+\frac{2 \lambda_{21}^{(1)}}{\lambda_{22}^{(1)} c_{1}} .
\end{aligned}
$$

These equations serves to provide $d_{2}$ in terms of the unkwown quantities $c_{2}, c_{1}, \lambda_{21}^{(1)}$ and $\lambda_{22}^{(1)}$. Note that if (9) is substituted into (3) then since it represents a solution to (3) it follows that

$$
\frac{\lambda_{11}^{(1)}}{c_{1}^{2}}-\frac{2 \lambda_{12}^{(1)}}{c_{1} d_{2}}+\frac{\lambda_{22}^{(1)}}{d_{2}^{2}}=\rho_{0}^{(1)}
$$


IIUM Engineering Journal, Vol. 12, No. 6, 2011: Special Issue in Science and Ethics

Jeffry

and if (13) is used to substitute for $1 / d_{2}$ in (15) and then into (8) so that (14) ensures (9) is a solution to (3) on the assumption that (7) is also solution to (3).

Let $d_{1}=\beta^{\prime} / \sin \gamma_{R}$ and $d_{2}=\beta^{\prime} / \cos \gamma_{R}$ where $\gamma_{R}$ is the angle of the reflection, then

$$
\tan \left(\gamma_{R}\right)=\frac{d_{2}}{d_{1}}=\frac{\tan \left(\gamma_{I}\right)}{1+2\left(\lambda_{12}^{(1)} / \lambda_{22}^{(1)}\right) \tan \left(\gamma_{I}\right)}
$$

and once $\gamma_{R}$ has been determined from this equation, the wave speed $\beta^{\prime}$ of the reflected wave may be readily determined from equation $\beta^{\prime}=d_{1} \sin \left(\gamma_{R}\right)$.

To include the influence of the inhomogeneous anisotropic alluvial valley in region 2 , the solution for the exterior of the deposit is put in the form

$$
v^{(1)}=v_{O}^{(1)}+v_{D}^{(1)}
$$

in which $v_{D}^{(1)}$ is the displacement due to the diffracted waves. In this region 2 , the displacement $v^{(2)}=v_{R}^{(2)}$ will be caused by the refracted waves.

\section{INTEGRAL EQUATION}

Proceeding further as in Clements and Larsson for the region $\mathcal{R}_{1}$ with boundary $\mathcal{C}_{1}$ and outward pointing normal components $n_{1}$ and $n_{2}$, the integral equation corresponding to $(3)$ is

$$
\tau v^{(1)}(a, b)=\int_{C_{1}}\left[\lambda_{i j}^{(1)} \frac{\partial V^{(1)}}{\partial x_{j}} n_{i} v^{(1)}-\lambda_{i j}^{(1)} \frac{\partial v^{(1)}}{\partial x_{j}} n_{i} V^{(1)}\right] d S
$$

where $\tau=1$ if $(a, b) \in \mathcal{R}_{1}$ and $0<\tau<1$ if $(a, b) \in \mathcal{C}_{1}$. The fundamental solution of $V^{(1)}$ is given by

$$
V^{(1)}=\frac{\iota}{4} K^{(1)}\left[H_{0}^{2}\left(\bar{v}^{(1)} R^{(1)}\right)+H_{0}^{2}\left(\bar{v}^{(1)}{ }_{\bar{R}}^{(1)}\right)\right]
$$

Where, 
IIUM Engineering Journal, Vol. 12, No. 6, 2011: Special Issue in Science and Ethics

$$
\begin{aligned}
& R^{(1)}=\left[\left(x_{1}-a\right)^{2}+\frac{\lambda_{11}^{(1)}}{\lambda_{22}^{(1)}}\left(x_{2}-b\right)^{2}-\frac{2 \lambda_{12}^{(1)}}{\lambda_{22}^{(1)}}\left(x_{1}-a\right)\left(x_{2}-b\right)\right]^{\frac{1}{2}}, \\
& \bar{R}^{(1)}=\left[\left(x_{1}-a\right)^{2}+\left(\frac{\lambda_{12}^{(1)}}{\lambda_{22}^{(1)}}\right)^{2}\left(x_{2}-b\right)^{2}-\frac{2 \lambda_{12}^{(1)}}{\lambda_{22}^{(1)}}\left(x_{1}-a\right)\left(x_{2}-b\right)+\right. \\
& K^{(1)}=\frac{\left.\left(x_{2}+b\right)^{2}\left(\frac{\lambda_{11}^{(1)} \lambda_{22}^{(1)}-\lambda_{12}^{(1)^{2}}}{\lambda_{22}^{(1)^{2}}}\right)\right]^{\frac{1}{2}}}{\lambda_{11}^{(1)} \lambda_{22}^{(1)}-\lambda_{12}^{(1)^{2}}}, \\
& \bar{v}^{(1)}=\left[\rho_{0}^{(1)} \omega^{2} K^{(1)}\right]^{\frac{1}{2}}
\end{aligned}
$$

and $H_{0}^{2}$ denotes the Hankel function of the second kind of order zero.

Furthermore, for the region $\mathcal{R}_{2}$ with boundary $C_{2}$ and outward pointing normal components $n_{1}$ and $n_{2}$, the integral equation corresponding to (6) is

$$
\begin{aligned}
K^{(2)} v^{(2)}(a, b)= & \int_{C_{2}}\left[\lambda_{i j}^{(2)}\left(\alpha_{1}^{(2)} x_{1}+\alpha_{2}^{(2)} x_{2}+\alpha_{3}^{(2)}\right)^{2} \frac{\partial V^{(2)}}{\partial x_{j}} n_{i} v^{(2)}-\right. \\
& \left.\lambda_{i j}^{(2)}\left(\alpha_{1}^{(2)} x_{1}+\alpha_{2}^{(2)} x_{2}+\alpha_{3}^{(2)}\right)^{2} \frac{\partial v^{(2)}}{\partial x_{j}} n_{i} V^{(2)}\right] d S,
\end{aligned}
$$

where

$$
\begin{aligned}
& V^{(2)}=\frac{\iota}{4}\left(\alpha_{1}^{(2)} x_{1}+\alpha_{2}^{(2)} x_{2}+\alpha_{3}^{(2)}\right)^{-1} H_{0}^{2}\left(\bar{v}^{(2)} R^{(2)}\right),(25) \\
& R^{(2)}=\left[\left(x_{1}-a\right)^{2}+\frac{\lambda_{11}^{(2)}}{\lambda_{22}^{(2)}}\left(x_{2}-b\right)^{2}-\frac{2 \lambda_{12}^{(2)}}{\lambda_{22}^{(2)}}\left(x_{1}-a\right)\left(x_{2}-b\right)\right]^{\frac{1}{2}}, \\
& \bar{v}^{(2)}=\left[\frac{\rho_{0}^{(2)} \omega^{2} \lambda_{22}^{(2)}}{\lambda_{11}^{(2)} \lambda_{22}^{(2)}-\lambda_{12}^{(2)^{2}}}\right]^{\frac{1}{2}} .
\end{aligned}
$$


Here, the value of $K^{(2)}$ may be determined by the help of solution of (6)

$$
w^{(2)}=\frac{\iota}{4}\left(\alpha_{1}^{(2)} x_{1}+\alpha_{2}^{(2)} x_{2}+\alpha_{3}^{(2)}\right)^{-1} H_{0}^{2}\left(\bar{v}^{(2)} S^{(2)}\right),
$$

where

$$
S^{(2)}=\left[x_{1}{ }^{2}+\frac{\lambda_{11}^{(2)}}{\lambda_{22}^{(2)}} x_{2}{ }^{2}-\frac{2 \lambda_{12}^{(2)}}{\lambda_{22}^{(2)}} x_{1} x_{2}\right]^{\frac{1}{2}} .
$$

Thus, using (28) in (24) in we obtain

$$
\begin{aligned}
K^{(2)}=\left[w^{(2)}(a, b)\right]^{-1} & \int_{C_{2}}\left[\lambda_{i j}^{(2)}\left(\alpha_{1}^{(2)} x_{1}+\alpha_{2}^{(2)} x_{2}+\alpha_{3}^{(2)}\right)^{2} \frac{\partial V^{(2)}}{\partial x_{j}} n_{i} w^{(2)}-\right. \\
& \left.\lambda_{i j}^{(2)}\left(\alpha_{1}^{(2)} x_{1}+\alpha_{2}^{(2)} x_{2}+\alpha_{3}^{(2)}\right)^{2} \frac{\partial w^{(2)}}{\partial x_{j}} n_{i} V^{(2)}\right] d S,
\end{aligned}
$$

By applying equation (18) and its fundamental solution (19) in the region 1 (outside of the valley) then the only non-zero integral is the integral over the valley's interface boundary (Sommerfeld radiation condition). If we denote this interface boundary as curve $\mathcal{C}_{1}$ and valley's free boundary as $\mathcal{C}_{F}$ and specifying the normal components $n_{1}$ and $n_{2}$ pointing outward of the valley's boundary, thus (18) and (24) on the valley's boundary are

$$
\frac{1}{2} v^{(1)}(a, b)=\int_{C_{1}}\left[\lambda_{i j}^{(1)} \frac{\partial V^{(1)}}{\partial x_{j}} n_{i} v^{(1)}-\lambda_{i j}^{(1)} \frac{\partial v^{(1)}}{\partial x_{j}} n_{i} V^{(1)}\right] d S,
$$

and

$$
\begin{gathered}
K^{(2)}\left[v^{(2)}(a, b)\right]=\int_{C_{1}+C_{F}}\left[\lambda_{i j}^{(2)}\left(\alpha_{1}^{(2)} x_{1}+\alpha_{2}^{(2)} x_{2}+\alpha_{3}^{(2)}\right)^{2} \frac{\partial V^{(2)}}{\partial x_{j}} n_{i} v^{(2)}-\right. \\
\left.\lambda_{i j}^{(2)}\left(\alpha_{1}^{(2)} x_{1}+\alpha_{2}^{(2)} x_{2}+\alpha_{3}^{(2)}\right)^{2} \frac{\partial v^{(2)}}{\partial x_{j}} n_{i} V^{(2)}\right] d S .
\end{gathered}
$$

The equation (31) and (32) together with the continuity equations 


$$
\begin{gathered}
v^{(1)}=v^{(2)}, \\
\lambda_{i j}^{(1)} \frac{\partial v^{(1)}}{\partial x_{j}} n_{i}=\lambda_{i j}^{(2)}\left(\alpha_{1}^{(2)} x_{1}+\alpha_{2}^{(2)} x_{2}+\alpha_{3}^{(2)}\right)^{2} \frac{\partial v^{(2)}}{\partial x_{j}} n_{i},
\end{gathered}
$$

and traction free boundary condition on $x_{2}=0$

$$
\lambda_{i j}^{(2)}\left(\alpha_{1}^{(2)} x_{1}+\alpha_{2}^{(2)} x_{2}+\alpha_{3}^{(2)}\right)^{2} \frac{\partial v^{(2)}}{\partial x_{j}} n_{i}=0
$$

may be used to solve for displacement and stress over the interface boundary $\boldsymbol{C}_{\mathbf{1}}$ and displacement along traction free surface $\boldsymbol{x}_{\mathbf{2}}=\mathbf{0}$. Once this has been done, we can obtain the value of the displacement $\boldsymbol{v}^{(\mathbf{1})}$ and/or $\boldsymbol{v}^{(2)}$ at all points $(\mathbf{a}, \mathbf{b})$ in the half space $\boldsymbol{x}_{\mathbf{2}}>0$ through equation (18) and (24).

\section{NUMERICAL RESULTS}

Suppose we have a semi circular valley (region 2 in Fig. 1 which is defined by nondimensional quantities which satisfy equation $\left(x_{1}-2\right)^{2}+x_{2}^{2} \leq 1$. Furthermore, suppose that the materials properties are non dimensional quantities $\lambda_{i j}^{(\Omega)}, \rho_{0}^{(\Omega)}, \alpha_{1}^{(\Omega)}, \alpha_{2}^{(\Omega)}, \alpha_{3}^{(\Omega)}$, $\Omega=1,2$ and the normalfrequency is defined by

$$
\eta=\frac{\omega}{\pi \beta^{(1)}}
$$

where $\beta^{(1)}$ is given by (8), then the numerical results are ready to be calculated.

Using the boundary element method by using 80 segments of straight line on the interface boundary and 70 segments on the free valley boundary, we obtain the numerical results as shown in Fig. 2 up to Fig. 9. These results generated by involving four kinds of alluvial valley's materials and two angles of the incident waves. The first material of the valley is homogeneous material with $\alpha_{1}^{(1)}=0.00, \alpha_{2}^{(1)}=0.00, \alpha_{3}^{(1)}=1.00$. The second material is inhomogeneous material with the inhomogeneity varies to $x_{1}$ direction only. This used $\alpha_{1}^{(2)}=0.50, \alpha_{2}^{(2)}=0.00, \alpha_{3}^{(2)}=0.00$. The third material is inhomogeneous material with in-homogeneity varies to $x_{2}$ direction and using $\alpha_{1}^{(2)}=0.00, \alpha_{2}^{(2)}=$ $0.50, \alpha_{3}^{(2)}=1.00$. The last material is inhomogeneous material with in-homogeneity varies to $x_{1}$ and $x_{2}$ directions by using $\alpha_{1}^{(2)}=0.50, \alpha_{2}^{(2)}=0.50, \alpha_{3}^{(2)}=0.00$. The results shown in figure 2 up to figure 5 are using these kinds materials respectively with incident waves angle $\gamma_{I}=0^{\circ}$ while figure 6 up to figure 9 are generated using the same materials 
IIUM Engineering Journal, Vol. 12, No. 6, 2011: Special Issue in Science and Ethics

Jeffry

as in figure 2 to figure 5 respectively but with incident waves angle $\gamma_{I}=30^{\circ}$. The others materials specification are $\lambda_{11}^{(1)}=0.12, \lambda_{12}^{(1)}=0.00, \lambda_{22}^{(1)}=0.12, \rho_{0}^{(1)}=3.00, \lambda_{11}^{(2)}=$ $0.02, \lambda_{12}^{(2)}=0.00, \lambda_{22}^{(2)}=2.00, \rho_{0}{ }^{(2)}=2.00$.

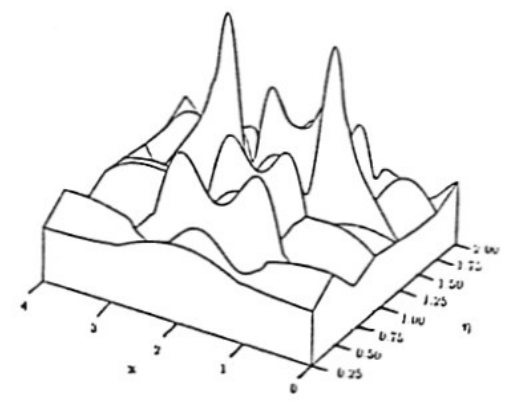

Fig. 2: Effect of homogeneous valley with $\gamma_{I}=0^{\circ}$

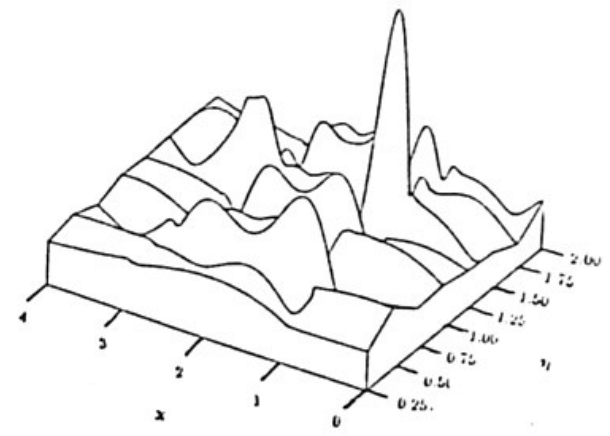

Fig. 3: Effect of inhomogeneous valley with $\gamma_{I}=0^{\circ}$

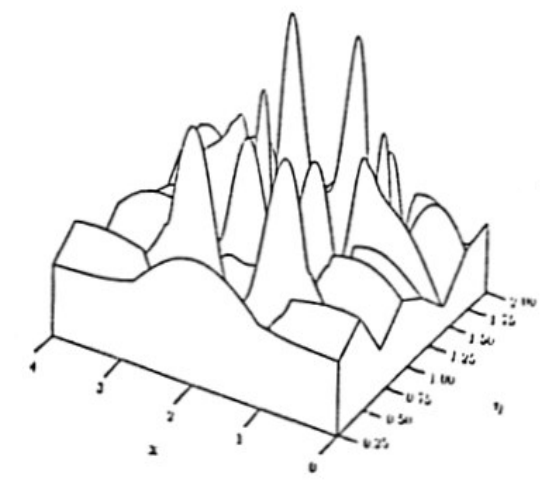

Fig. 4: Effect of inhomogeneous valley with $\gamma_{I}=0^{\circ}$ 


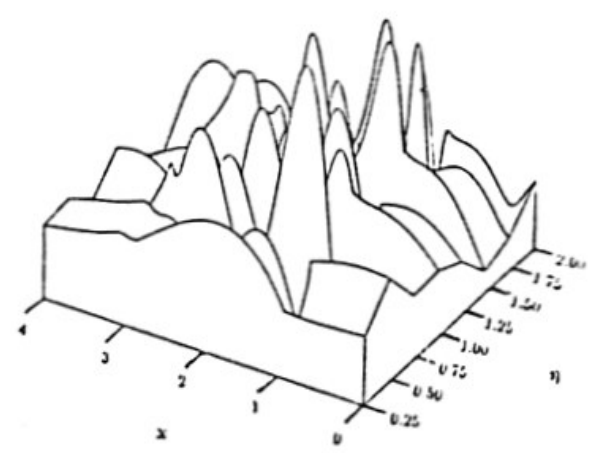

Fig. 5: Effect of inhomogeneous valley with $\gamma_{I}=0^{\circ}$

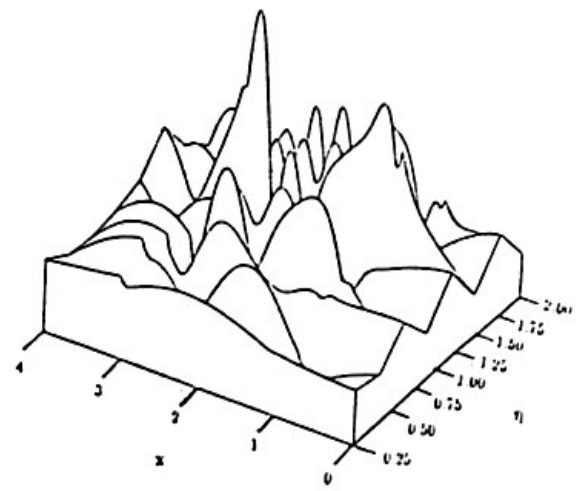

Fig. 6: Effect of homogeneous valley with $\gamma_{I}=30^{\circ}$

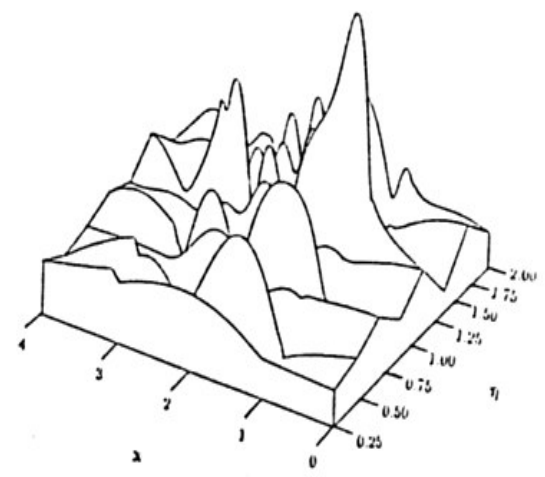

Fig. 7: Effect of inhomogeneous valley with $\gamma_{I}=30^{\circ}$ 


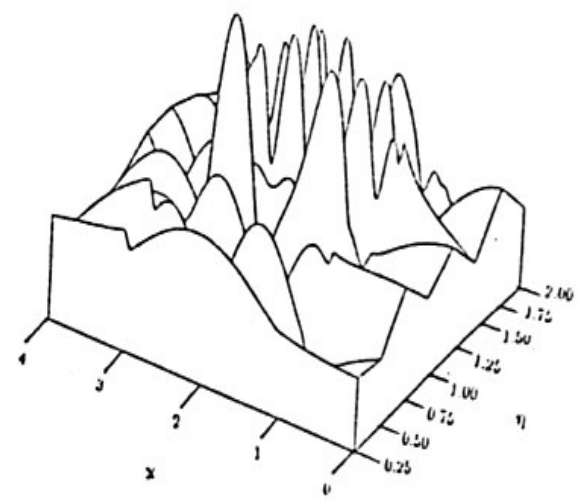

Fig. 8: Effect of inhomogeneous valley with $\gamma_{I}=30^{\circ}$

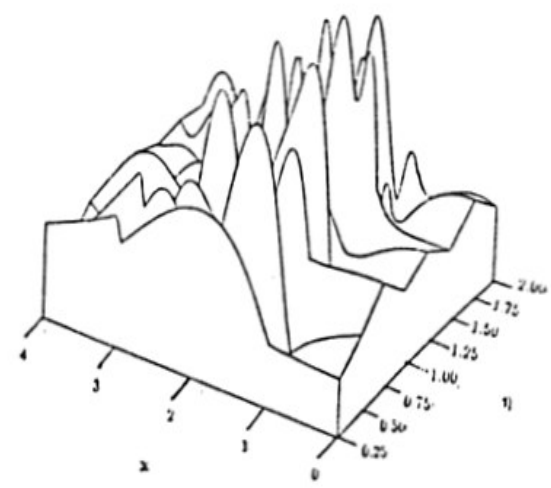

Fig. 9: Effect of inhomogeneous valley with $\gamma_{I}=30^{\circ}$

\section{CONCLUSION}

The results in Fig. 2 up to Fig. 9 show that amplification effects are significantly influenced by the materials specification and the angle of the incident waves. The flexibility of the boundary integral element methods is an advantage in dealing with irregularities of the alluvial valley. For such kind of alluvial surface, the method described above can be directly used to obtain the amplification effect.

The flexibility of the boundary integral element methods is an advantage in dealing with irregularities of the alluvial valley. For such kind of alluvial valley's surfaces can be directly used to obtain the amplification effect.

\section{ACKNOWLEDGEMENT}

The author wish to thank the Ministry of National Education of the Republic Indonesia for financial support in order to publish this paper. 
IIUM Engineering Journal, Vol. 12, No. 6, 2011: Special Issue in Science and Ethics

Jeffry

\section{REFERENCES}

[1] M.A. Bravo, Sánchez-Sesma andChávez F. J. García, "Ground motion on stratified alluvial deposit for incident $S H$ waves," Bull. Seism. Soc. Am. 78, (1988)436-450.

[2] M.D. Trifunac, "Surface motion of a semi-cylindrical alluvial valley for incident plane $S H$ waves," Bull. Seism. Soc. Am. 61, (1971) 1755-1770.

[3] Sánchez-Sesma, and J. A. Esquivel, "Ground motion on alluvialvalleys under incident plane SH waves," Bull. Seism. Soc. Am. 69,(1979) 1107-1120.

[4] H.L. Wong and P.C. Jennings, "Effects of canyon topography on strong ground motion," Bull. Seism. Soc. Am. 65, (1975) 1239-1257.

[5] H.L. Wong and M.D. Trifunac, "Interaction of a shear wall with the soil for incident plane SH waves : Elliptical foundation," Bull. Seism. Soc. Am. 64, (1974) 1825-1842.

[6] H.L. Wong and M.D. Trifunac, "Surface motion of a semi-elliptical alluvial valley for incident planeSH waves," Bull. Seism. Soc. Am. 64, (1974) 1389-1408.

[7] H.L. Wong, M.D. Trifunac and B. Westermo, "Effects of surface and subsurface irregularities on the amplitude of monochromatic waves," Bull. Seism. Soc. Am. 67, (1977) 353-368.

[8] D.L. Clements, and A. Larsson, "Ground motion on alluvial valleys under incident plane SH waves,"J. Austral. Math. Soc. Ser. B 33, (1991), 240-253.

[9] F. Ursell, "On the exterior problems of acoustic," Proc. Camb. Phil Soc 74, (1973), 117-125. 